\section{Geometry of}

Time and Space

By A. A. ROBB

57 text-figures. 21 s. net

The Optical Basis of

The Theory of

Valency

By R. De L. KRONIG

67 figures (including 6 plates), 25 tables

16s. net

Cambridge Series of Physical Chemistry

Generalized

Hypergeometric Series

BY W. N. BAILEY

6s. 6d. net

Cambridge Mathematical Tracts No. 32

\section{Interpolatory Function Theory}

BY J. M. WHITTAKER 6s. 6d, net

Cambridge Mathematical Tracts No. 33

\section{The Theory of \\ Atomic Spectra}

BY E. U. CONDON \& G. H. SHORTLEY

Illustrated. 30 s. net

Electron Emission and Adsorption Phenomena

By J. H. de BOER

21s. net

Cambridge Series of Physical Chemistry

$A_{i 1}$ Investigation into the Factors

in Tests involving

The Visual Perception of Space

By A. A. H. EL KOUSSY

23 text-figures, 12 tables. $8 s$. 6d. net

The British Journal of Psychology

Monograph Supplements, No. XX

\section{Experimental \\ Optics}

A Manual for the Laboratory

BY G. F. C. SEARLE

16s. net

Cambridge Physical Series 


\title{
CONTENTS
}

BAKER, Prof. H. F. On the Contacts of Circles

Babbage, D. W. Some Quartic Primals and Associated Cremona Transformations of Four-dimensional Space . . . . . . . . .

Frith, RoNALD. The Relations between the Invariants of Two Surfaces in $(1, n)$ Cyclio Correspondence . . . . . . . . . . .

Verbiunsky, S. Solution of a Moment Problem for Bounded Functions .

Goldstern, S. The Stability of Viscous Fluid Flow under Pressure between Parallel Planes

Pekerts, Chatm L. On the Stability Problem in Hydrodynamics . . .

Greien, A. E. The Gliding of a Plate on a Stream of Finite Depth. Part II. (With 9 Figures in the Text)

Hrrscheren, H. O. A Generalization of Picard's Method of Successive Approximation.

WeInstern, A. On the Symmetries of the Solutions of a certain Variational Problem.

Born, M. On the Linearization of the Energy Density of the Electromagnetic Field

Motr, N. F. Thermal Properties of an Incompletely Degenerate Fermi Gas. (With 2 Figures in the Text)

Harmere, W. On the Radiation Frnitted by a Multipole and its Angular Momentum

INFELD, L. The New Action Function and the Unitary Field Theory. (With 1 Figure in the Text) . . . . . . . . .

Senrde, G. F. C. A Maximum-Minimum Method of Determining the Cardinal Points of a Lens system. (With 4 Figures in the Text)

Fowler, Prof. R. H. Adsorption Isotherms. Critical Conditions. (With 1 Figure in the Text)

Rosmers, J. K. The Dissociation Equilibrium of Hydrogen and its Adsorption on Tungsten . . . . . . . . . . .

JAEGER, J. C. and HuxMre, H. R. On the Annihilation of Positrons. (With 1 Figure in the Text)

ArNot, F. L. The Errors of Approximation in Jeffreys's Phases. (With 6 Figures in the Text).

AnuISON, SAMUEL K. Experiments on the Efficiencies of Production and the Half-Lives of Radio-Carbon and Radio-Nitrogen

\section{CAMBRIDGE UNIVERSITY PRESS \\ OAMBRIDGE, AND BENTLEY HOUSE, LONDON \\ OANADA AND INDIA: MACMILLAN}

\author{
First Printed in Great Britain at the University Press, Cambridge. \\ Reprinted by offset-litho \\ by Percy Lund Humphries \& Co., Ltd.
}

